\title{
A Study of Routine Work of Counselors in Vocational Colleges in the
}

New Era

Tang Jing ${ }^{1, \text { a }}$

${ }^{1}$ Chongqing Business Vocational College, Chongqing, 401331

Key words: vocational colleges; counselors; mental health; routine management

\begin{abstract}
Political counselors in vocational colleges are directly responsible for students' ideological and political education and management. To enhance their professional ability and help them adapt to various changes in the new era, this thesis analyzes responsibilities of counselors and conducts a summary of their work characteristics and mental health education. What's more, taking myself as an example, I also proposes some suggestions.
\end{abstract}

\section{Introduction}

Ideological and political education is one important aspect of counselor's work in vocational colleges, including education of ideology, politics, morality, etc. In practical work, counselors integrate ideological and political work into routine teaching and management of students. Furthermore, multiple approaches are used to inform students of the latest news and social hot spots to guide them to deal with problems in life with scientific theories. It can strengthen their political awareness and ability to judge between right and wrong so that what they have learned can be put into practice. Therefore, it is of great necessity for counselors in vocational colleges to possess sound political theories and profound moral quality, otherwise students' ideological and political education can't be effectively implemented.

As the old saying goes, one is never too old to learn. Colleges and universities serve as the important base for talent cultivation. Students are supposed not only to grasp modern technologies and theories, but to use what they have learned to solve problems in life and find out their own learning methods. It aims to cultivate the ability of thinking. For college students, teaching in class is one way to gain knowledge. And it is more important to learn on their own. So counselors should resort to different methods to guide students, such as arousing their interest, stimulating their initiative, correcting learning attitude, forming good habits, etc.

In China, to improve employment is one of the most important teaching objectives in colleges and universities. Everything done is to make them better prepared for future jobs and adapt to the society. Therefore, counselors should play their role to the fullest during this process. With regard to employment, provide students with practical instructions and help them know themselves. What's more, supply them with more employment information, widen employment channels and enhance their competitiveness from various aspects. Encourage students to participate in meaningful social practice to improve their ability to adapt to the society. Set up courses that are related to employment which can impart more professional skills to students. Moreover, attend career planning competition to help students with their jobs from different channels.

Campus cultural activities are rich and colorful. Either participation or planning can enrich students' after-school life and even improve their abilities except for professional skills. But only a small number of students can take an active part in these activities while most of them can’t make it 
because of laziness or timidness. At this time, guidance and encouragement from counselors are urgently needed. Only with counselor's support in personnel, materials, finance and techniques, can campus cultural activities go smoothly.

\section{Work Characteristics of Counselors in Vocational Colleges}

Work of counselors was focused on student teaching and management before. However, it is more about providing service for students due to changes in charge system and traditional ideas. Apart from previous ideological teaching and management, it is of greater significance to improve students' moral quality and guide them to foster right outlook on life, world and values. What's more, offer them help in study and life and help them attend to various contradictions and psychological problems; provide employment information and lead them to set up right view of employment.

With the development of times, our life is filled with various modern communication tools, such as cellphones, computers, etc. They also have changed and affected college life to a large extent. As counselors in the new era, they must keep up the pace of times and apply the tools to student management. In today's colleges, these tools are so common that communication between counselors and students is not limited to face-to-face any more. For example, they are able to inform students of routine affairs in QQ group and communicate with students via Fetion, WeChat, Weibo, etc., which can improve efficiency and, at the same time, avoid certain defects existing in traditional ways of communication.

The majority of modern college students are the only child of their families, the apple of parents' eye. It is good to have unique personality. But they aren't strong enough to stand adversity and are easy to go impulsive and extreme. What's worse, lack of interpersonal communication skills, lofty ideals and sense of responsibility has resulted in great pressure of employment. They have been used to being spoiled and acting at will. What's more, college students are faced with increasingly serious mental health problems because of living environment, employment pressure, unfairness in society, etc. All of these factors have brought much more difficulty to the management of college students.

\section{Current Status of Mental Health of Vocational College Students}

At the beginning of college life, it is necessary to carry out psychological test to fresh students. In this way, the underlying problems can be found out for timely and effective treatment. Specifically speaking, the following mental health problems are common among students in vocational colleges.

The generation after 90s are mostly the only child of the family. Growing up in a spoiling environment, they, self-centered and rebellious, resent instruction from the teachers and refuse help from classmates and friends. On the other hand, they hope to show their ability and value through all possible ways. But they capability is limited and are inclined to panic, even will have a nervous breakdown when confronted with setbacks. With ordinary academic performance, most students in vocational colleges are pessimistic, non-confident, but eager for self improvement. While struggling between reality and dream, they appear agitated, inferior to others and worried. At the same time, with a simple mind, they do things without much consideration and tend to be impulsive when getting along with others. They will feel disappointed and lonely once nobody supports or recognizes their opinions and suggestions.

In most cases, the generation after 90s are the "King” of the family. They are usually self-centered. With strong self awareness, they long for independent life. But college life is different 
from that in senior high school, including the range involved, related methods, learning environment, and the people they contact. On account of immature outlook on life and values as well as the effect from family, some students can't deal with the relations with roommates and the opposite sex properly, thus leading to conflicts with them. Some even resort to extreme solutions as a result of psychological imbalance.

As higher education enjoys greater popularity, the number of graduates keeps increasing year after year. Employment positions tend to be stable while the economy of China is slowing down. The problem of finding a job bothers many college students. The fact that the diploma of vocational college students is much less competitive than that of undergraduates also means stronger pressure when it comes to find a job. As a result, vocational college students are suffering various mental distress. They worry they can't find a satisfactory job after graduation; they feel inferior, restless, dependent and at a loss; they try to escape from the reality and think about dropping out of school to work; some students are even so depressed that they run to extremes.

Students who were born after 90s can venture to challenge life, authority and pursue excitement and changes. They like being free. Therefore, they have strong hands-on skills, active thinking and innovative awareness. However, it is easy for them to be influenced by outside world and care too much about others' opinions and even lose themselves. Some students hold no firm beliefs. All of their energy is only put in meaningful things, which makes them short-sighted and lack ambitions. Moreover, they are short of sense of responsibility and mission and not active enough. Few people, except for parents and teachers, tell them to care other things in addition to study.

Various communication ways emerge one after another. Colleges can go with the tide of the times, take advantage of the Internet and adopt the approaches that are easier for students to accept for psychological treatment. Most students in vocational colleges are fond of surfing the internet, which, therefore, serves as a good choice for colleges to do psychological guidance, such as QQ, WeChat and so on. Such methods can avoid the embarrassment and timidness brought by face-to-face communication and is more effective to explore ideas at the bottom of their hearts.

Secondly, help the generation after 90 s to set up lofty ideals and improve social

communication ability. Based on students' mental state, counselors should proceed systematic psychological guidance and take it as supplementary means of counseling. It is not only beneficial to more efficient communication, but can improve student's social communication ability and help them adapt to college life and social needs quickly. During this process, lofty ideals can be established on purpose.

Thirdly, take the initiative to care and help students born after 90s. Psychological

Counseling is a good choice to show concern for students. They will feel they are being paid attention to, which can enhance their self-identification and self-confidence in both study and interpersonal communication. Therefore, counselors should talk to students, guide them, know what's in their mind and gain their trust, thus realizing better education and instruction.

\section{Measures to Perfect Counseling Work}

Strengthen the learning of political theories of CPC and vocational education policies and fulfill studies on the theoretical and practical issues of party building. Work earnestly and be honest to become a qualified party member, which, in turn, will also help better carry out their own work. At the same time, keep the study of pedagogy and psychology to make it more scientific-based in work. Moreover, try to know more about students' majors in order to provide more professional and specific service.

After the reception of freshmen, help drillmasters to complete military training and students to 
adapt to college life. During this period, assessment of freshmen subsidies should be finished, which must be based on justice and fairness with zero objection. Set up a student cadre team who are responsible, capable and highly efficient. Make them perform their own duties well to guarantee an orderly class and work. What's more, strive to do better and for excellence. Hold a series of class meetings themed with studies on the theoretical and practical issues of party building and the education of freshmen. At the same time, encourage students to take an active part in all kinds of activities and find out the outstanding ones. Supervise and urge discipline inspector for check-up of morning and evening self-study as well as attendance. Everything must be faithfully recorded and handed in every week. The result will be announced in public. Commissary in charge of general affairs should check the dormitories every day, report to teachers and keep records. Conduct hierarchical management, from individuals, head of the dormitory to life secretary. Hold class meetings, visit dormitories and communicate with students through multiple means to have a deeper understanding of students, thus providing more specific help for them.

Starting with the education of freshmen, provide different career plans and guidance for students from different majors and foundations. First of all, popularize large-scale education of entrepreneurship, from hierarchical filtering to cultivation of the best candidates. Provide practice opportunities for those with both ability and awareness of entrepreneurship. For example, they can start with attending business marketing competition and then go forward step by step. For students from underprivileged families, start with psychological counseling and encourage them to succeed from practice and find confidence in success, thus adapting themselves to society. For those special students with psychological problems, arrange student cadres for one-on-one service. Then hold regular conversations with them with the assistance of teachers from school psychological counseling center and help them with their jobs. Finally, for students with excellent academic performance, encourage them to attend the exam to gain a bachelor's degree, even postgraduate exam to improve themselves.

Counselors have double identities of cadres and teachers, which makes it necessary for everyone of them to not only offer qualified service for student, but pay close attention to enhancing their knowledge and scientific capability. Therefore, apart from their own duties and responsibilities, counselors should also devote themselves to study, master new theories and approaches about students work, strengthen their own professional knowledge and take an active part in all kinds of social activities to accumulate life experiences and narrow the difference between themselves and college students in modern era.

To start with, to improve management of students, counselors must make efforts to conduct research, such as publishing academic papers about students education and management and, at the same time, learning to apply research subjects. What's more, we should apply our own majors to practical work. Taking myself as an example, I have combined legal education and students management. With legal publicity as starting point, cultivate their legal consciousness and guide them to analyze questions with legal thinking in the form of theme class meetings or lectures based on real cases concerning students management. And teach them to depend on the weapon of laws to protect their own interests in study, daily life and work.

In a word, counselors need to strengthen themselves, combining theories and practice and learning from coworkers. With the help from different sides, make a summary of student management to gradually develop their own style and characteristics.

\section{Reference}

[1] Zhu Zhiwen. Analysis of the current situation of College Students' psychological health 
education and Its Countermeasures [J]. Journal of Tongling Polytechnic, 2012 (2)

[2] Zhao Xuelian. Analysis on the mode of psychological health education in Higher Vocational College [J]. Journal of Heilongjiang Institute of education, 2011 (1)

[3] gold. Mental health problems of contemporary college students [J]. Journal of Lanzhou Institute of Education, 2013 (2)

[4] Du ting. Analysis and Countermeasures of the ideological and political quality of College Counselors: [D]. Ji'nan: Shandong University, 2011

[5] Zhang Rui, Li Nan. Research on the construction of college counselor team in the perspective of interdisciplinary [J].school party building and ideological education, 2013, (1)

[6] Liu zhe Xi. Study on the improvement of the quality of College Students' counselors after 90 [D]. Changsha: Hunan University, 2012 